Open Access

\title{
Increased CCL2, CCL3, CCL5, and IL-1 $\beta$ cytokine concentration in piriform cortex, hippocampus, and neocortex after pilocarpine-induced seizures
}

Gabriel M. Arisi $1^{1,2,3,4}$, Maira L. Foresti ${ }^{1,2,3,4}$, Khurshed Katki ${ }^{1,2,3}$ and Lee A. Shapiro 1,2,3*

\begin{abstract}
Background: Cytokines and chemokines play an important role in the neuroinflammatory response to an initial precipitating injury such as status epilepticus (SE). These signaling molecules participate in recruitment of immune cells, including brain macrophages (microglia), as well as neuroplastic changes, deterioration of damaged tissue, and epileptogenesis. This study describes the temporal and brain region pattern expression of numerous cytokines, including chemokines, after pilocarpine-induced seizures and discusses them in the larger context of their potential involvement in the changes that precede the development of epilepsy.
\end{abstract}

Findings: Adult rats received pilocarpine to induce SE and 90 min after seizure onset were treated with diazepam to mitigate seizures. Rats were subsequently deeply anesthetized and brain regions (hippocampus, piriform cortex, neocortex, and cerebellum) were freshly dissected at 2, 6, and $24 \mathrm{~h}$ or 5 days after seizures. Using methodology identical to our previous studies, simultaneous assay of multiple cytokines (CCL2, CCL3, CCL5, interleukin IL-1 $\beta$, tumor necrosis factor (TNF-a)), and vascular endothelial growth factor (VEGF) was performed and compared to control rats. These proteins were selected based on existing evidence implicating them in the epileptogenic progression. A robust increase in CCL2 and CCL3 concentrations in the hippocampus, piriform cortex, and neocortex was observed at all time-points. The concentrations peaked with a $\sim 200$-fold increase $24 \mathrm{~h}$ after seizures and were two orders of magnitude greater than the significant increases observed for CCL5 and $\mathrm{IL}-1 \beta$ in the same brain structures. TNF-a levels were altered in the piriform cortex and neocortex (24 h) and in the hippocampus ( 5 days) after SE.

Conclusions: Pilocarpine-induced status epilepticus causes a rapid increase of multiple cytokines in limbic and neocortical regions. Understanding the precise spatial and temporal pattern of cytokines and chemokine changes could provide more viable therapeutic targets to reduce, reverse, or prevent the development of epilepsy following a precipitating injury.

Keywords: Chemokine, Cytokine, Interleukin, Epilepsy, Seizure, Inflammation, Multiplex

\footnotetext{
* Correspondence: Ishapiro@medicine.tamhsc.edu

${ }^{1}$ Texas A\&M University Health Science Center, Department of Surgery,

Temple, TX 76504, USA

${ }^{2}$ Baylor Scott and White Health Care, Department of Neurosurgery, Temple,

TX 76504, USA

Full list of author information is available at the end of the article
}

\section{Ciomed Central}

(c) 2015 Arisi et al. This is an Open Access article distributed under the terms of the Creative Commons Attribution License (http://creativecommons.org/licenses/by/4.0), which permits unrestricted use, distribution, and reproduction in any medium, provided the original work is properly credited. The Creative Commons Public Domain Dedication waiver (http:// creativecommons.org/publicdomain/zero/1.0/) applies to the data made available in this article, unless otherwise stated. 


\section{Findings} Introduction

Secretion of cytokines is a fundamental component of the inflammatory response in the nervous system [1-4]. These proteins are important immunomodulators, and chemokines, a special class of cytokines, also possess chemoattractant properties. Following an initial precipitating injury such as status epilepticus (SE), alterations occur to the milieu of these neuroinflammatory proteins. Of the numerous functional outcomes attributed to these alterations, neuroplasticity has been implicated to play a prominent role in the epileptogenic progression. Other changes that have also been implicated in pathogenesis include vascular permeability, angiogenesis, and immune responses that contribute to tissue damage [2]. Considering that SE increases subsequent seizure susceptibility and the likelihood of developing epilepsy, immunomodulatory signaling proteins are garnering great interest as therapeutic targets to treat neuropathology and the epileptogenic progression [1, 3]. Further evidence in support of the potential for these proteins as therapeutic targets is found in patients with epilepsy. In these patients, studies have observed increased levels of chemokines CCL2, CCL3, and CCL5 (among others) in the hippocampus, other temporal lobe structures, and neocortex [4]. Moreover, elevated cytokines such as interleukin 6 (IL-6) and tumor necrosis factor (TNF) can be detected in serum [1], and previous experimental studies in rodents have yielded promising results regarding the potential therapeutic efficacy of targeting these particular inflammatory molecules. Considering these data, a greater understanding of the temporal and spatial changes of these proteins can yield more efficacious treatment options, as well as more precise targeting.

After the acute and early phases of SE, the brain typically enters into a latent period that precedes the development of spontaneous seizures. During this period, it has been suggested that neuroplastic and neuroinflammatory changes provide a substrate for hyperexcitable neural networks [5, 6]. Indeed, our

Table 1 Average cytokine concentration in $\mathrm{pg} / \mu \mathrm{g}$ of total protein

\begin{tabular}{|c|c|c|c|c|c|c|c|c|c|c|}
\hline \multicolumn{2}{|l|}{ Analytes } & \multirow[t]{2}{*}{ Brain region } & \multicolumn{2}{|l|}{$2 \mathrm{~h}$} & \multicolumn{2}{|l|}{$6 \mathrm{~h}$} & \multicolumn{2}{|l|}{$24 \mathrm{~h}$} & \multicolumn{2}{|l|}{5 days } \\
\hline Cytokines & Chemokines & & Control & SE & Control & SE & Control & SE & Control & SE \\
\hline & $\mathrm{CCL} 2$ & Piriform & 3.6 & 10.7 & 3.7 & 34.8 & 3.7 & 694.8 & 3.6 & 22.8 \\
\hline & & Hippocampus & 3.7 & 16.3 & 4.4 & 81.6 & 2.2 & 243.8 & 4.4 & 26.8 \\
\hline & & Neocortex & 2.9 & 21.7 & 3.5 & 97.0 & 3.7 & 933.3 & 3.8 & 15.5 \\
\hline & & Cerebellum & 1.4 & 1.8 & 1.4 & 1.9 & 2.8 & 4.0 & 3.8 & 5.7 \\
\hline & CCL3 & Piriform & 0.4 & 24.3 & 1.7 & 29.8 & 0.2 & 50.3 & 0.3 & 15.6 \\
\hline & & Hippocampus & 0.5 & 31.4 & 1.2 & 30.6 & 0.2 & 42.2 & 0.1 & 29.3 \\
\hline & & Neocortex & 0.9 & 32.3 & 0.9 & 23.3 & 0.1 & 37.7 & 0.3 & 22.1 \\
\hline & & Cerebellum & 0.2 & 0.2 & 0.0 & 0.0 & 0.0 & 0.9 & 0.0 & 0.0 \\
\hline & CCL5 & Piriform & 6.7 & 8.2 & 8.1 & 10.3 & 6.0 & 13.8 & 6.6 & 10.1 \\
\hline & & Hippocampus & 4.9 & 5.8 & 5.8 & 5.9 & 6.6 & 10.6 & 4.5 & 6.7 \\
\hline & & Neocortex & 8.6 & 8.9 & 7.9 & 10.5 & 8.2 & 14.2 & 8.4 & 8.2 \\
\hline & & Cerebellum & 7.1 & 5.9 & 7.1 & 6.2 & 7.2 & 6.0 & 6.8 & 5.8 \\
\hline \multirow[t]{4}{*}{$I L-1 \beta$} & & Piriform & 5.0 & 7.7 & 5.2 & 7.8 & 6.2 & 12.2 & 6.1 & 6.7 \\
\hline & & Hippocampus & 5.5 & 8.5 & 6.0 & 8.5 & 5.9 & 7.7 & 5.8 & 6.4 \\
\hline & & Neocortex & 6.4 & 10.0 & 5.6 & 9.1 & 5.7 & 13.4 & 6.4 & 8.0 \\
\hline & & Cerebellum & 6.0 & 6.4 & 5.0 & 5.7 & 5.3 & 6.5 & 5.7 & 6.7 \\
\hline \multirow[t]{4}{*}{ TNF } & & Piriform & 1.3 & 1.0 & 0.7 & 0.8 & 1.2 & 0.6 & 1.1 & 1.6 \\
\hline & & Hippocampus & 1.6 & 1.6 & 1.3 & 1.9 & 2.5 & 1.6 & 1.5 & 2.8 \\
\hline & & Neocortex & 1.2 & 1.5 & 1.0 & 1.5 & 0.7 & 1.5 & 2.0 & 1.5 \\
\hline & & Cerebellum & 1.0 & 1.0 & 0.5 & 0.4 & 0.6 & 0.5 & 0.6 & 0.9 \\
\hline \multicolumn{11}{|c|}{ (Signal protein) } \\
\hline \multirow[t]{4}{*}{ VEGF } & & Piriform & 0.9 & 0.7 & 0.9 & 0.5 & 0.9 & 1.1 & 0.9 & 0.6 \\
\hline & & Hippocampus & 0.8 & 0.7 & 0.6 & 0.5 & 0.9 & 0.9 & 0.7 & 0.7 \\
\hline & & Neocortex & 0.7 & 0.5 & 0.7 & 0.6 & 0.6 & 0.7 & 0.9 & 0.9 \\
\hline & & Cerebellum & 0.3 & 0.7 & 0.5 & 0.7 & 0.5 & 0.5 & 0.6 & 0.7 \\
\hline
\end{tabular}


previous studies have implicated the neuroinflammatory response in the hippocampus to provide a substrate for the aberrant sprouting of basal dendrites from immature and mature granule cells [7]. Considering the complex interactions that occur among the cytokines both in immune and nervous systems, the most efficacious method for examining their presence in epileptogenesis is through simultaneous multiplex immunoassay [8]. We previously demonstrated elevated hippocampal concentrations of chemokine $\mathrm{C}-\mathrm{C}$ motif ligand 2 (CCL2) during the acute phase after SE [7]. This report extends these previous findings to further identify acute and early alterations to cytokine concentrations in the hippocampus, cerebellum, and piriform cortex, brain structures that are known to be involved in seizures and epilepsy.

\section{Methods}

Animals and seizure induction

Male Sprague-Dawley rats, weighing 230-235 g at the beginning of experiments were used in this study. The experimental procedure was approved by the IACUC of the Texas A\&M University Health Science Center (protocol \#2008-002-R).

SE was induced as previously described [7]. Animals were treated with pilocarpine hydrochloride in a single dose of $320 \mathrm{mg} / \mathrm{kg}$ i.p. or saline. The onset of SE was considered when animals exhibited a class 3 motor seizure in Racine's scale of limbic seizures [9]. Only animals that experienced stage 5 seizures were used for analysis $(n=48)$. Ninety minutes after SE onset, rats were treated with diazepam $(10 \mathrm{mg} / \mathrm{kg})$ to mitigate seizures; control animals also received diazepam.

\section{Tissue harvest}

Animals were deeply anesthetized using Euthasol (pentobarbital sodium and phenytoin, $1 \mathrm{ml} / \mathrm{kg}$ ) and decapitated 2,6 , and $24 \mathrm{~h}$ or 5 days $(n=12$ per timepoint) after diazepam treatment. The brain was rapidly removed from the skull, and the hippocampus, cerebellum, piriform cortex, and a large slice of neocortex close to the midline containing the retrosplenial, cingulate, and primary motor cortex were dissected and immediately frozen.

\section{Cytokine analyses}

Simultaneous measuring of different cytokines in brain regions was performed as previously described [8]. The following cytokines were assayed: CCL2, CCL3, CCL5, IL-1 $\beta$, TNF- $\alpha$, and vascular endothelial growth factor (VEGF) (Table 1) in tissue homogenates using a MILLIPLEX MAP kit (Millipore, Billerica, MA, USA) on a BIOPLEX 200 analyzer (BioRad, Hercules, CA, USA). The tissue concentration of each analyte was normalized
Table 2 Cytokine concentration ratio of SE/control animals

\begin{tabular}{|c|c|c|c|c|c|c|}
\hline \multicolumn{2}{|l|}{ Analytes } & \multirow[t]{2}{*}{ Brain region } & \multirow[t]{2}{*}{$2 \mathrm{~h}$} & \multirow[t]{2}{*}{$6 \mathrm{~h}$} & \multirow[t]{2}{*}{$24 \mathrm{~h}$} & \multirow[t]{2}{*}{5 days } \\
\hline Cytokines & Chemokines & & & & & \\
\hline & CCL2 & Piriform & $3^{* *}$ & $9^{* *}$ & $186^{* *}$ & $6^{* *}$ \\
\hline & & Hippocampus & $4^{*}$ & $18^{* *}$ & $108^{* *}$ & $6^{* *}$ \\
\hline & & Neocortex & $7^{* *}$ & $27^{* *}$ & $252^{* *}$ & 4 \\
\hline & & Cerebellum & 1 & 1 & 1 & 1 \\
\hline & CCL3 & Piriform & $60^{* *}$ & $18^{* *}$ & $228^{* *}$ & $54^{* *}$ \\
\hline & & Hippocampus & $69^{* *}$ & $25^{* *}$ & $211^{* *}$ & $238^{* *}$ \\
\hline & & Neocortex & $35^{* *}$ & $25^{* *}$ & $272^{* *}$ & $86^{* *}$ \\
\hline & & Cerebellum & 1 & 1 & 1 & 1 \\
\hline & CCL5 & Piriform & 1 & 1 & $2^{* *}$ & $2^{*}$ \\
\hline & & Hippocampus & 1 & 1 & $2^{*}$ & 1 \\
\hline & & Neocortex & 1 & 1 & $2^{*}$ & 1 \\
\hline & & Cerebellum & 1 & 1 & 1 & 1 \\
\hline \multirow[t]{4}{*}{ IL-1 $\beta$} & & Piriform & $2^{*}$ & 1 & $2^{*}$ & 1 \\
\hline & & Hippocampus & $2^{*}$ & $2^{*}$ & 1 & 1 \\
\hline & & Neocortex & $2^{*}$ & $2^{*}$ & $2^{* *}$ & 1 \\
\hline & & Cerebellum & 1 & 1 & 1 & 1 \\
\hline \multirow[t]{4}{*}{ TNF } & & Piriform & 1 & 1 & $1 / 2^{*}$ & 1 \\
\hline & & Hippocampus & 1 & 1 & $1 / 2^{*}$ & $2^{*}$ \\
\hline & & Neocortex & 1 & 2 & 2 & 1 \\
\hline & & Cerebellum & 1 & 1 & 1 & 1 \\
\hline
\end{tabular}

\begin{tabular}{llllll} 
Signal protein & Piriform & 1 & 1 & 1 & 1 \\
VEGF & Hippocampus & 1 & 1 & 1 & 1 \\
& Neocortex & 1 & 1 & 1 & 1 \\
& Cerebellum & 1 & 1 & 1 & 1 \\
\hline
\end{tabular}

${ }^{*} p<0.05 ;{ }^{* *} p<0.001$

to the total protein concentration measured with a Bradford assay and presented as a proportion of cytokines in picograms $(\mathrm{pg})$ per microgram $(\mu \mathrm{g})$ of total protein \pm SEM. Student's $t$ test was employed to detect statistical differences in values of control and experimental groups.

\section{Results}

The results revealed significant increases in the concentration of numerous cytokines at different time-points in several of the brain regions examined (Tables 1 and 2).

Tissue concentration of CCL2 was significantly increased in seizure animals at all time-points, and in all brain regions, except in the cerebellum. Concentrations peaked at $24 \mathrm{~h}$ after SE in the piriform cortex hippocampus, and midline neocortex. Five days after seizures, CCL2 levels were still significantly elevated in the piriform cortex, hippocampus, and neocortex but had declined from the 24-h peak levels (Fig. 1). 


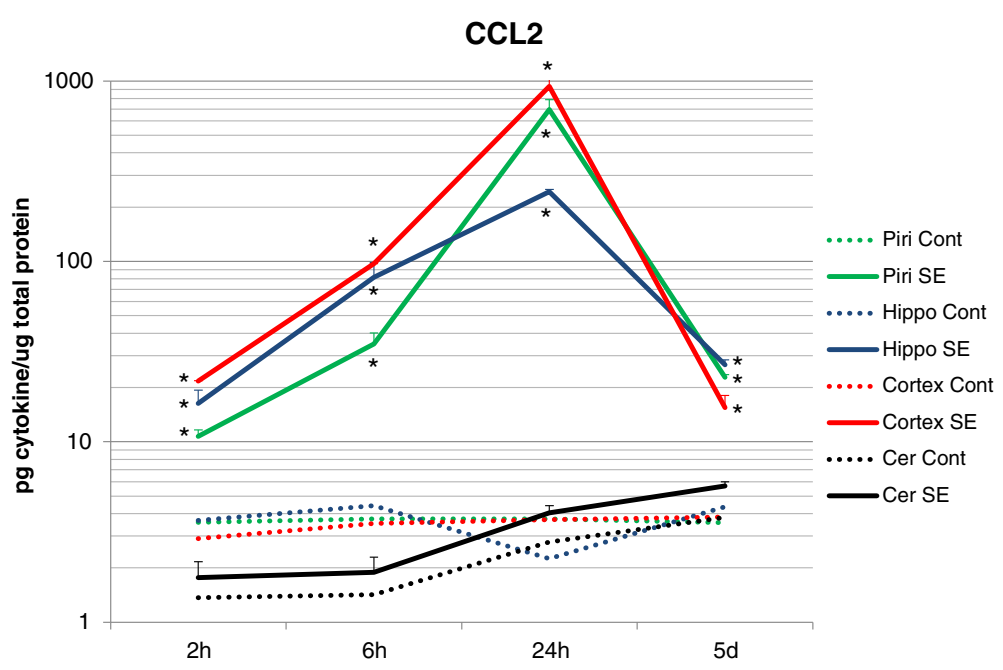

Fig. 1 CCL2 concentrations presented with a log scale to illustrate the magnitude of increased CCL2 relative to the other cytokines examined. An increase of 3-7 times the basal levels was observed $2 \mathrm{~h}$ after SE, 10-25 times the control levels $6 \mathrm{~h}$ after SE, and reached a peak $24 \mathrm{~h}$ after SE in the hippocampus, piriform cortex, and neocortex with increases of $\sim 100-, \sim 200-$, and $\sim 250-$ fold, respectively. Five days after seizures, CCL2 concentration was still significantly elevated in the piriform cortex, hippocampus, and neocortex ( ${ }^{*} p<0.001$ in all cases). No significant alterations to CCL2 concentrations were observed in the cerebellum

The chemokine CCL3 presented a larger increase at earlier time-points relative to CCL2 protein observed $2 \mathrm{~h}$ after SE in the piriform cortex, hippocampus, and midline neocortex (Fig. 2). At $6 \mathrm{~h}$ after SE, increase in the same areas was followed by a peak concentration $24 \mathrm{~h}$ after $\mathrm{SE}$ in all regions, except the cerebellum. Five days after SE, concentrations of CCL3 remained significantly elevated in the hippocampus, piriform cortex, and midline neocortex, but to a lesser extent than at the 24-h peak (Fig. 2).

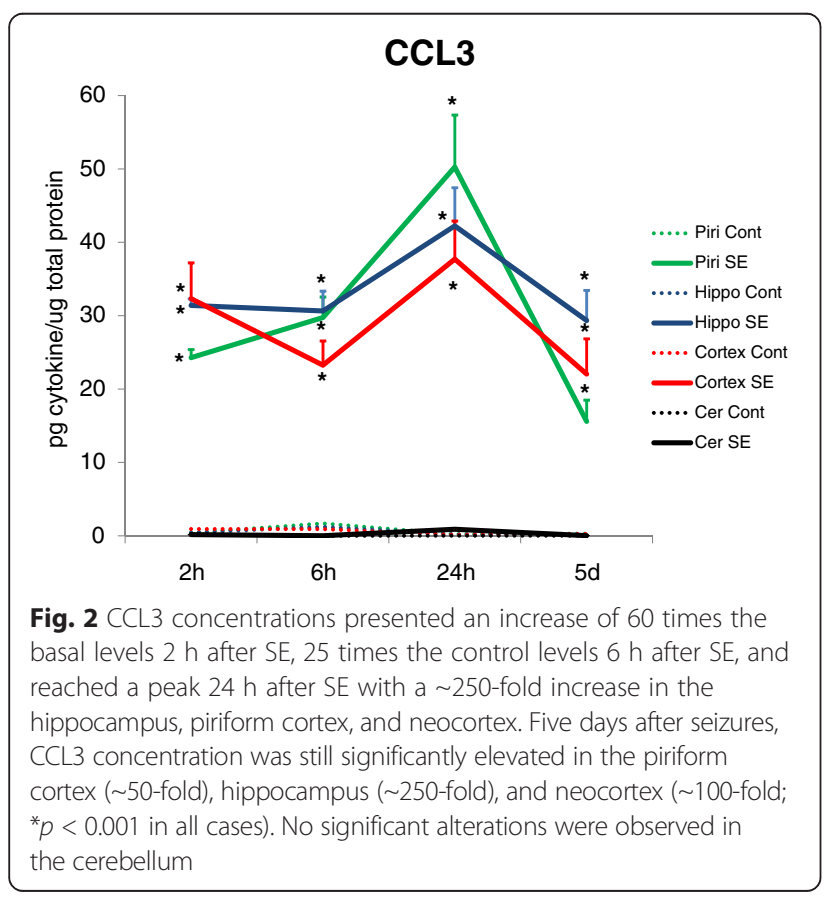

Concentration of CCL5 was significantly elevated at $24 \mathrm{~h}$ after SE in the piriform cortex and neocortex. No significant alterations were observed in either the hippocampus or the cerebellum. Five days after SE, the CCL5 concentration was still significantly elevated in the piriform cortex but returned close to control levels in other regions (Fig. 3).

The concentration of IL- $1 \beta$ was significantly elevated $2 \mathrm{~h}$ after SE in the neocortex, piriform cortex, and hippocampus, but not in the cerebellum (Fig. 4). Concentrations of IL- $1 \beta$ were significantly elevated $6 \mathrm{~h}$ after SE in the neocortex and hippocampus, but not in the piriform cortex or cerebellum (Fig. 4). The peak concentration was observed $24 \mathrm{~h}$ after SE in the piriform cortex and neocortex. Five days after seizures, IL-1 $\beta$ levels returned to levels similar to control rats in all brain regions (Fig. 4).

Analysis of TNF- $\alpha$ levels revealed significant concentration decrease in the piriform cortex and hippocampus 24 $h$ after SE and a significant concentration increase in the hippocampus 5 days after SE (Table 1). No significant alterations in VEGF levels were observed at any of the timepoints, nor in any of the regions analyzed (Tables 1 and 2).

\section{Discussion}

Simultaneous analysis of multiple cytokines in different brain regions, at different time-points after SE, revealed significant alterations in the concentration of CCL2, CCL3, CCL5, IL-1 $\beta$, and TNF- $\alpha$. CCL2 and CCL3 showed the largest concentration increases in the piriform cortex, hippocampus, and neocortex that peaked at $24 \mathrm{~h}$ after SE. CCL5 and IL-1 $\beta$ were also significantly elevated in these brain regions, although the 


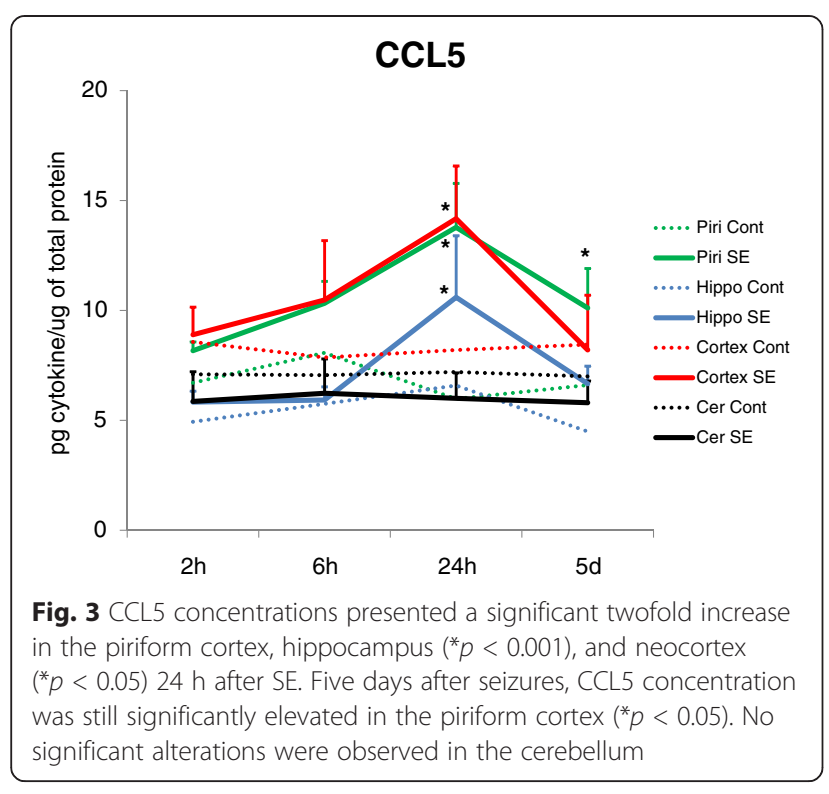

increases were orders of magnitude lower relative to CCL2 and CCL3. These novel data in the rat pilocarpine SE model are consistent with findings in human epileptic patients, where microarray analyses showed upregulation of genes $\mathrm{ccl} 3$ and $\mathrm{ccl} 4$ in surgically removed hippocampus [10]. Similarly, animal studies showed increased CCL2 and CCL3 mRNA that peak 1 day after electrically induced SE [11], and following kainic acid-induced seizures in rats, the gene for $c c l 2$ was upregulated in entorhinal, perirhinal, posterior piriform cortices and hippocampus, where its expression level

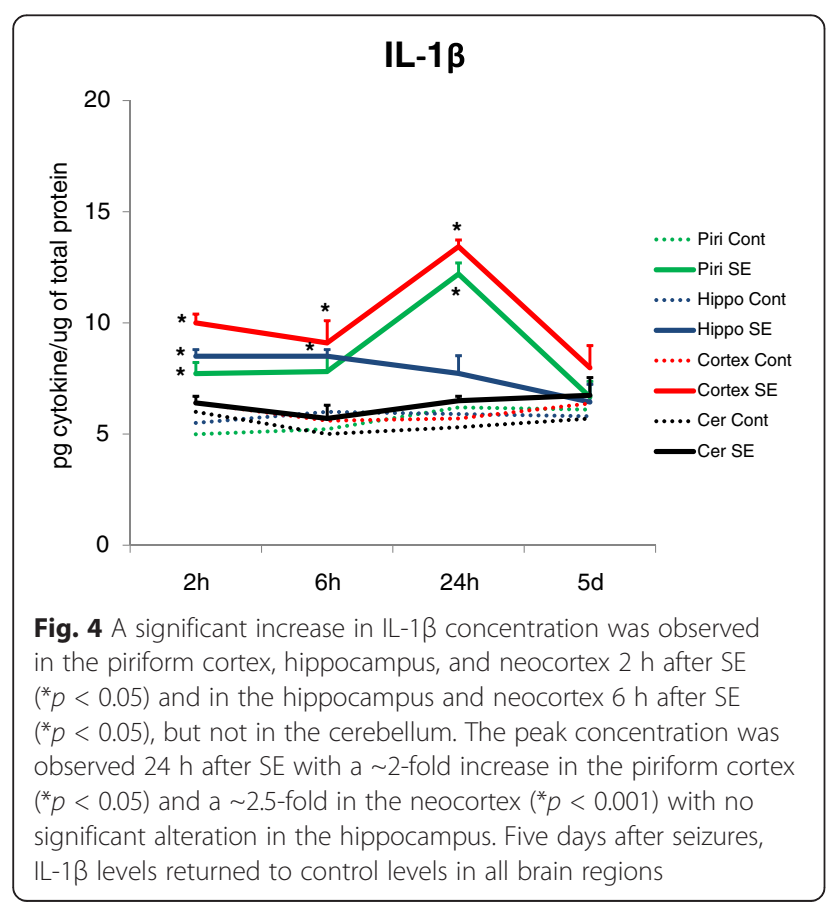

was the highest relative to the other genes examined [12]. Therefore, future translational studies can selectively target one or more of these inflammatory proteins in the pilocarpine SE model.

Further highlighting the clinical relevance of these chemokines, elevated CCL2 protein was observed in the temporal lobe and hippocampus from patients with intractable epilepsy [13], and both CCL2 and CCL3 proteins were elevated in temporal lobe epilepsy patients measured with multiplex assay [4]. We have also previously shown that CCL2 and its receptor CCR2 were elevated in the rat hippocampus 5 days after seizures in rats [8], whereas other studies demonstrated increased CCL3 protein within the first $2 \mathrm{~h}$ after pilocarpine injection in mice [14]. Results consistent with these findings were also found in other experimental models of temporal lobe epilepsy, such as tetanic stimulation of the hippocampus [11] and following kainic acid-induced seizures [5]. Thus, there is substantial accumulating evidence that changes in these cytokines may play an important role in epileptogenesis and thus may represent viable therapeutic targets.

From a functional perspective, it is possible that CCL2 is involved in direct impairment of neuronal survival in epileptogenic structures. For example, CCL2 activates caspase signaling pathways [15], which can contribute directly to cell death. CCL2 can also influence glia activation and the ensuing inflammation [16], which results in uncoupling of gap junctions between astrocytes and thus a reduced calcium buffering potential by the astrocytic network observed in temporal lobe epilepsy patients [17]. Further evidence in support for direct functional impairment attributed to CCL2 elevation was reported in a study in which expression by astrocytes in transgenic mice impairs synaptic plasticity in the hippocampus [18]. Indeed, a study that inhibited CCL2 secretion with pyrrolidine dithiocarbamate prior to pilocarpine-induced SE demonstrated beneficial outcomes with less microglial activation and decreased neuronal damage [19]. While such experimentation may not be clinically viable, it does provide evidence for the therapeutic potential of targeting CCL2 to improve epileptogenic outcomes.

Targeting the seizure-induced increase in CCR5 may be another putative therapeutic target to ameliorate the epileptogenic progression. The chemokine CCL5 is chemotactic to T cells, eosinophils, and basophils. Consistent with the findings in the present study, there is an upregulation of CCR5 expression after kainic acidinduced seizures especially in hippocampal formation neurons and glial cells [20] and after pilocarpineinduced seizures in hippocampal astrocytes [21]. Interestingly, the use of RNA interference to lower CCR5 expression in rats protected against kainic acid-induced 
seizures by decreasing hippocampal neuronal loss and macrophage/microglial infiltration [22]. The fact that CCR5-knockout mice did not show the same protection against inflammatory hippocampal injury suggests that compensatory mechanisms may render it necessary to target multiple inflammatory molecules to achieve optimal benefit [23].

The result of elevated IL-1 $\beta$ following SE is consistent with previous studies showing that increased concentration of IL- $1 \beta$ after seizures exerts a pro-epileptogenic action, and blocking of IL-1 $\beta$ presented anticonvulsive effects while exogenous application of the cytokine worsened electrographic seizure development $[2,4]$. In contrast, the results from the current study were inconsistent with previous reports of increased VEGF after pilocarpine-induced seizures [24]. One possible explanation for this discrepancy is that the current study examined total VEGF protein in brain homogenates, whereas the latter study observed elevated cellular VEGF in neurons and astrocytes [24]. Thus, it is possible that the altered VEGF expression observed is a qualitative rather than a quantitative one.

\section{Conclusions}

The data from this short report shows, for the first time, elevated CCL2 and CCL3, as well as increased CCL5, IL$1 \beta$, and differentially altered TNF- $\alpha$. It is becoming increasingly clear that the neuroinflammatory response after an initial precipitating injury such as SE plays an important role in nervous tissue pathology. Understanding the temporal and spatial expression patterns of the neuroinflammatory milieu is essential to develop improved therapeutic interventions following these types of injury. Therefore, simultaneous measurement of multiple cytokines from different brain regions is especially important to elucidate the extensive, intertwined, and complex interactions among the inflammatory proteins. Such studies will enable subsequent studies that target multiple cytokine/chemokines at different time-points and possibly different brain regions to achieve optimal therapeutic efficacy.

\footnotetext{
Abbreviations

CCL: C-C motif chemokines; CCL2/MCP-1: monocyte chemoattractant protein-1; CCL3/MIP-1a: macrophage inflammatory protein 1 alpha; CCL5/ RANTES: regulated upon activation normal T cell expressed; CCR: CCL receptor; IL: interleukin; TNF: tumor necrosis factor; VEGF: vascular endothelial growth factor.
}

\section{Competing interests}

The authors declare that they have no competing interests.

\section{Authors' contributions}

GMA carried out the experimental animal studies and statistical analyses and drafted the manuscript. MLF helped with the animal studies and drafting of the manuscript. KK carried out the cytokine immunoassays and analyses. LAS participated in the design and coordination of the study and drafted the manuscript with GMA. All authors read and approved the final manuscript.

\section{Acknowledgements}

This material is the result of the work supported by the use of facilities at the Central Texas Veterans Health Care System, Temple, TX, USA. The work in the authors' laboratory is/was supported by grants from The American Heart Association (09SDG2370076) and Scott and White Hospital. We thank Amanda Ruch for the technical expertise.

\section{Author details}

${ }^{1}$ Texas A\&M University Health Science Center, Department of Surgery, Temple, TX 76504, USA. 'Baylor Scott and White Health Care, Department of Neurosurgery, Temple, TX 76504, USA. ${ }^{3}$ Central Texas Veterans Health Care System, Temple, TX 76504, USA. ${ }^{4}$ Present address: Department of Physiology, Escola Paulista de Medicina, Universidade Federal de São Paulo, Rua Pedro de Toledo 669, Lab 3A, São Paulo, SP 04039-032, Brazil.

Received: 2 December 2014 Accepted: 17 June 2015

Published online: 02 July 2015

\section{References}

1. Sinha S, Patil SA, Jayalekshmy V, Satishchandra P. Do cytokines have any role in epilepsy? Epilepsy Res. 2008;82:171-6.

2. Minami M, Kuraishi Y, Satoh M. Effects of kainic acid on messenger RNA levels of IL-1 beta, IL-6, TNF alpha and LIF in the rat brain. Biochem Biophys Res Commun. 1991;176:593-8.

3. Fabene PF, Bramanti P, Constantin G. The emerging role for chemokines in epilepsy. J Neuroimmunol. 2010;224:22-7.

4. Kan AA, de Jager W, de Wit M, Heijnen C, van Zuiden M, Ferrier C, et al. Protein expression profiling of inflammatory mediators in human temporal lobe epilepsy reveals co-activation of multiple chemokines and cytokines. J Neuroinflammation. 2012;9:207.

5. Somera-Molina KC, Nair S, Van Eldik L, Watterson DM, Wainwright MS. Enhanced microglial activation and proinflammatory cytokine upregulation are linked to increased susceptibility to seizures and neurologic injury in a 'two-hit' seizure model. Brain Res. 2009;1282:162-72.

6. Foresti ML, Arisi GM, Shapiro LA. Role of glia in epilepsy-associated neuropathology, neuroinflammation and neurogenesis. Brain Res Rev. 2010;66:115-22.

7. Foresti ML, Arisi GM, Katki K, Montañez A, Sanchez RM, Shapiro LA. Chemokine CCL2 and its receptor CCR2 are increased in the hippocampus following pilocarpine-induced status epilepticus. J Neuroinflammation. 2009;6:40.

8. Mukherjee S, Katki K, Arisi GM, Foresti ML, Shapiro LA. Early TBl-induced cytokine alterations are similarly detected by two distinct methods of multiplex assay. Front Mol Neurosci. 2011:4:21.

9. Racine RJ. Modification of seizure activity by electrical stimulation. II. Motor seizure. Electroencephalogr Clin Neurophysiol. 1972;32:281-94.

10. van Gassen KL, de Wit M, Koerkamp MJ, Rensen MG, van Rijen PC, Holstege FC, et al. Possible role of the innate immunity in temporal lobe epilepsy. Epilepsia. 2008;49:1055-65.

11. Gorter JA, van Vliet EA, Aronica E, Breit T, Rauwerda H, da Silva FHL, et al. Potential new antiepileptogenic targets indicated by microarray analysis in a rat model for temporal lobe epilepsy. J Neurosci. 2006;26:11083-110.

12. Sharma AK, Searfoss GH, Reams RY, Jordan WH, Snyder PW, Chiang AY, et al. Kainic acid-induced F-344 rat model of mesial temporal lobe epilepsy: gene expression and canonical pathways. Toxicol Pathol. 2009;37:776-89.

13. Wu Y, Wang $X, M o X, X i Z, X i a o ~ F, ~ L i ~ J$, et al. Expression of monocyte chemoattractant protein-1 in brain tissue of patients with intractable epilepsy. Clin Neuropathol. 2008;27:55-63.

14. Xu JH, Long L, Tang YC, Zhang JT, Hut HT, Tang FR. CCR3, CCR2A and macrophage inflammatory protein (MIP)-1a, monocyte chemotactic protein-1 (MCP-1) in the mouse hippocampus during and after pilocarpine-induced status epilepticus (PISE). Neuropathol Appl Neurobiol. 2009;35:496-514.

15. Sheehan JJ, Zhou C, Gravanis I, Rogove AD, Wu YP, Bogenhagen DF, et al. Proteolytic activation of monocyte chemoattractant protein-1 by plasmin underlies excitotoxic neurodegeneration in mice. J Neurosci. 2007;27:1738-45

16. Kalehua AN, Nagel JE, Whelchel LM, Gides JJ, Pyle RS, Smith RJ, et al. Monocyte chemoattractant protein-1 and macrophage inflammatory protein-2 are involved in both excitotoxin-induced neurodegeneration and regeneration. Exp Cell Res. 2004;297:197-211. 
17. Bedner $\mathrm{P}$, Dupper $\mathrm{A}$, Hüttmann $\mathrm{K}$, Müller J, Herde MK, Dublin $\mathrm{P}$, et al. Astrocyte uncoupling as a cause of human temporal lobe epilepsy. Brain. 2015;138:1208-22.

18. Nelson TE, Hao C, Manos J, Ransohoff RM, Gruol DL. Altered hippocampal synaptic transmission in transgenic mice with astrocyte-targeted enhanced CCL2 expression. Brain Behav Immun. 2011;25 Suppl 1:S106-19.

19. LV R, Xu X, Luo Z, Shen N, Wang F, Zhao Y. Pyrrolidine dithiocarbamate (PDTC) inhibits the overexpression of MCP-1 and attenuates microglial activation in the hippocampus of a pilocarpine-induced status epilepticus rat model. Exp Ther Med. 2014;7:39-45.

20. Mennicken F, Chabot JG, Quirion R. Systemic administration of kainic acid in adult rat stimulates expression of the chemokine receptor CCR5 in the forebrain. Glia. 2002;37:124-38.

21. Kan AA, van der Hel WS, Kolk SM, Bos IW, Verlinde SA, van Nieuwenhuizen $\mathrm{O}$, et al. Prolonged increase in rat hippocampal chemokine signalling after status epilepticus. J Neuroimmunol. 2012;245:15-22.

22. Louboutin JP, Chekmasova A, Marusich E, Agrawal L, Strayer DS. Role of CCR5 and its ligands in the control of vascular inflammation and leukocyte recruitment required for acute excitotoxic seizure induction and neural damage. FASEB J. 2010;25:737-53.

23. Chen Z, Yu S, Bakhiet M, Winblad B, Zhu J. The chemokine receptor CCR5 is not a necessary inflammatory mediator in kainic acid-induced hippocampal injury: evidence for a compensatory effect by increased CCR2 and CCR3. J Neurochem. 2003;86:61-8.

24. Croll SD, Goodman JH, Scharfman HE. Vascular endothelial growth factor (VEGF) in seizures: a double-edged sword. Adv Exp Med Biol. 2004;548:57-68.

\section{Submit your next manuscript to BioMed Central and take full advantage of:}

- Convenient online submission

- Thorough peer review

- No space constraints or color figure charges

- Immediate publication on acceptance

- Inclusion in PubMed, CAS, Scopus and Google Scholar

- Research which is freely available for redistribution 